\title{
Features of Interpersonal Cognition in People with High Interpersonal Sensitivity and Privileged Self: Personality Features of "Modern-Type" Depression
}

\author{
Shinji Sakamoto, Masaki Muranaka, Itsuki Yamakawa \\ Department of Psychology, College of Humanities and Sciences, Nihon University, Tokyo, Japan \\ Email: sakamoto.shinji@nihon-u.ac.jp
}

How to cite this paper: Sakamoto, S., Muranaka, M., \& Yamakawa, I. (2017). Features of Interpersonal Cognition in People with High Interpersonal Sensitivity and Privileged Self: Personality Features of "Modern-Type" Depression. Psychology, 8, 13901402.

https://doi.org/10.4236/psych.2017.89091

Received: June 20, 2017

Accepted: July 21, 2017

Published: July 24, 2017

Copyright @ 2017 by authors and Scientific Research Publishing Inc. This work is licensed under the Creative Commons Attribution International License (CC BY 4.0).

http://creativecommons.org/licenses/by/4.0/

\begin{abstract}
Since the 1990s, "modern-type" depression (MTD), which has different features from melancholic depression, has been reported and has become a mental health problem in Japan. Although psychological studies of MTD are very limited, previous studies have proposed Interpersonal Sensitivity (IS) and Privileged Self (PS) as personality features of MTD. IS and PS are measured by the Interpersonal Sensitivity/Privileged Self Scale (IPS), and the present study examined correlations of IPS scores with several personality scales to clarify the interpersonal cognition tendencies of people with high IS and PS. A total of 439 Japanese undergraduates participated in the study, answering several questionnaires including the IPS. Results showed that people with high IS scores were inclined to be concerned with how they were seen by others, tended to take notice of others, and had a weaker sense of independent self, but a stronger sense of interdependent self. These characteristics are thought to be common in anxiety as well as melancholic depression. People with high PS scores were more likely to disregard others and showed higher tendencies to dogmatism and a diffuse/avoidant identity style, which may be unique in MTD.
\end{abstract}

\section{Keywords}

Depression, Interpersonal Sensitivity, Personality, Self-Consciousness, Interpersonal Influence

\section{Introduction}

\section{1. "Modern-Type" Depression in Japan}

In Japan, psychiatrists have proposed two contrasting subtypes of depression: 
traditional-type depression (TTD) and "modern-type" depression (MTD; e.g., Kato et al., 2011). TTD is depression with melancholic features according to the DSM-IV (American Psychiatric Association, 2013), and is considered to be prototypical depression. On the other hand, some Japanese psychiatrists have indicated the existence of MTD, which differs from TTD (Table 1; see also Kato et al., 2016). MTD has been reported in Japan especially from 1990, and is now reported to be observed in other Asian countries or regions (e.g., Korea, Taiwan), Australia, and the United States (Kato et al., 2011). Although MTD is not recognized as a formal diagnosis in Japan, psychiatrists and psychologists are beginning to study MTD empirically (e.g., Sakamoto, Yamakawa, \& Muranaka, 2016), and diagnostic criteria for MTD have been proposed by Kato et al. (2016).

\subsection{Individual Differences in MTD: Interpersonal Sensitivity (IS) and Privileged Self (PS)}

As stated above, MTD has attracted attention from Japanese people and become a mental health problem in Japan (e.g., Mori, 2012a, 2012b); thus, psychological studies examining the onset of MTD are needed. Although psychological theories of depression already exist (e.g., Abramson, Alloy, \& Metalsky, 1990), these theories implicitly assume that depression is of the melancholic type. Thus, a

Table 1. A comparison of melancholic depression and "modern-type" depression in Japan.

\begin{tabular}{|c|c|c|}
\hline & $\begin{array}{l}\text { Melancholic depression } \\
\text { (Traditional-type depression: TTD) }\end{array}$ & "Modern-type" depression (MTD) \\
\hline Ages & Middle age (born before 1970) & Young age (born after 1970) \\
\hline \multirow{5}{*}{ Characters } & Love of order, models & Distress over rules/order \\
\hline & Sympathetic & Negative feelings toward order or model \\
\hline & Obsessive & Vague sense of omnipotence \\
\hline & Honest & Not hard worker to begin with \\
\hline & Hard worker & \\
\hline \multirow[t]{2}{*}{ Symptoms } & Agitation or retardation & Fatigue and not feeling good enough \\
\hline & Exhaustion and guilt & Avoidance and blame of others \\
\hline \multirow[t]{3}{*}{$\begin{array}{l}\text { Therapeutic } \\
\text { relationship }\end{array}$} & Resist diagnosis of depression & Cooperate with diagnosis of depression \\
\hline & When recovered, learn from experience of depression & Tend to self-check depressive symptoms \\
\hline & & $\begin{array}{l}\text { Have difficulty departing from diagnosis } \\
\text { (prefer to stay in "depression") }\end{array}$ \\
\hline \multirow[t]{2}{*}{ Drug response } & Usually good & Partial response \\
\hline & Complete remission & \\
\hline Cognition & $\begin{array}{l}\text { Obtaining a new sense of role } \\
\text { (e.g., self as a manager to self as a manager who has experienced depression) }\end{array}$ & $\begin{array}{l}\text { Have difficulty departing from } \\
\text { "I suffer from depression" }\end{array}$ \\
\hline \multirow[t]{2}{*}{ Prognosis } & Good response to rest and antidepressants & $\begin{array}{l}\text { Become chronically ill only with } \\
\text { rest and antidepressants }\end{array}$ \\
\hline & Ambivalent about change of environment & $\begin{array}{l}\text { Change of environment } \\
\text { rapidly improves symptoms }\end{array}$ \\
\hline
\end{tabular}

Note. With reference to Tarumi (2005), Tarumi \& Kanba (2005), and Kato et al. (2011). 
new theory is needed to explain MTD, which has different features to melancholic depression; Sakamoto, Yamakawa, and Muranaka (2014) proposed a new psychological theory attempting to explain the onset of MTD. According to this theory, a certain type of personality interacts with interpersonal stressors (i.e., negative evaluations from others), which then produces depressive symptoms similar to MTD. We describe the theory briefly below.

Under this theory, the personality type that was assumed to engender MTD was specified on the basis of the authors' previous study (Muranaka, Yamakawa, \& Sakamoto, 2015), and the features of this personality type were labeled "Interpersonal Sensitivity" and "Privileged Self." Interpersonal Sensitivity (IS) is defined as subsuming both of the following two characteristics: (a) a tendency to be excessively worried about others' negative evaluations, and (b) a tendency to excessively react (i.e., overreact) to such negative evaluations. People with high IS tend to be shocked and become depressed after receiving negative evaluations from others who have significant influence over them. People with high IS may be likely to be influenced by negative evaluations from others and feel depressed as a result. For example, when making mistakes at work, high-IS office workers are more likely to be worried about negative evaluations from their superiors and colleagues, which make them feel depressed. Such tendencies may be seen in both MTD and TTD.

However, MTD and TTD differ in Privileged Self (PS), which is defined as a tendency to pursue one's own pleasure at the expense of maintaining harmony with others. Consider the aforementioned office workers who make mistakes at work and feel depressed. If such workers are high in PS, they are strongly motivated to lessen their unpleasant experiences (i.e., the negative evaluations from others and the depressed mood) at the expense of maintaining harmony with their superiors and colleagues. Thus, they may contradict or blame the people who evaluated them negatively, and may be absent from the office in order to distract themselves from the office work which made them feel depressed. In contrast, if such office workers are low in PS, they may think that harmony with others is more important than pursuing their own pleasure. Thus, they may make efforts to reverse the negative evaluations of others; if they are successful in doing so, their depressed mood will lessen. Otherwise, they may blame themselves and apologize for not performing well; presenting self-blame is sometimes used in Japan as a means of solving interpersonal conflict, and such behavior may also improve others' evaluations of them. This kind of behaviors (i.e., making additional effort or engaging in self-blame) are typically seen in the case of TTD.

Although Sakamoto et al.'s theory may show promise in explaining the onset of MTD, the scale that measures IS and PS has only recently been developed (Muranaka, Yamakawa, \& Sakamoto, 2017; Yamakawa, Muranaka, \& Sakamoto, 2015), and empirical studies of the theory are anticipated.

\subsection{The Purpose of the Present Study}

IS and PS are measured by the Interpersonal Sensitivity/Privileged Self Scale 
(IPS; Muranaka et al., 2017; Yamakawa et al., 2015). As the reliability and validity of the IPS have already been reported (Muranaka et al., 2017; Yamakawa et al., 2015), in the present study we use this scale to examine the interpersonal characteristics of persons with high IS and PS.

In examining their interpersonal characteristics, we consider three separate aspects of cognition. In interpersonal situations, a person interacts with others, and may often consider how he/she is seen by others, especially when the others are important to him/her. Thus, the first aspect considered is self-consciousness. Subsequently, once interpersonal influences take hold between the person and others, the person may come to consider the relationship between the self and others. Thus, the second and third aspects are cognition about others in relation to the self, and cognition about the self in relation to others. For the first aspect, we examine correlations between IPS scores and the Interpersonal Sensitivity Measure (Boyce \& Parker, 1989), Public Self-Consciousness Scale (Fenigstein, Scheier, \& Buss, 1975), and Self-Preoccupation Scale (Sakamoto, 1998). For the second aspect, we examine correlations between IPS scores and the AssumedCompetence Scale (Hayamizu, Kino, Takagi, \& Tan, 2004). Finally, for the third aspect, we examine correlations between IPS scores and the Takata Independent/ Interdependent Self-Construal Scale (Takata, Omoto, \& Seike, 1996) and the Identity Style Inventory (Berzonsky, 1989).

As anti-depressants are somewhat ineffective in treating MTD (Table 1), methods of prevention and intervention drawing on psychological perspectives are needed. In planning such methods, knowledge of the interpersonal characteristics of persons with IS and PS is important, because these traits are thought to interact with interpersonal stressors to engender MTD (Sakamoto et al., 2014). Thus, in the present study, we administered several scales along with the IPS to test a number of correlational hypotheses.

\subsection{Hypotheses about IS}

Regarding the first aspect of interpersonal cognition investigated here, self-consciousness, people with high IS are thought to be generally nervous about interpersonal relations, which predicts a positive correlation with scores on the existing scale of interpersonal sensitivity, the Interpersonal Sensitivity Measure. People high in IS are also thought to be concerned about their public self, the self that is observable by others. Thus, IS scores were expected to correlate positively with scores on the Public Self-consciousness Scale. It is noteworthy that public self-consciousness reflects the tendency to focus on public aspects of the self, but not the duration of such self-focused attention. As some researchers have pointed out (Ingram, 1990; Sakamoto, 1998), it is the duration of self-focused attention that plays a more important role in the maintenance of depressive symptoms. Thus, in explaining the onset of MTD, the duration of self-focused attention also needs to be considered; we predicted a positive correlation between IS and the Self-Preoccupation Scale, which reflects the duration of selffocused attention. 
For the second aspect of cognition, cognition about others in relation to the self, we predicted a negative correlation between IS and the Assumed-Competence Scale, which measures the degree to which a person disregards others. People high in IS may be more influenced by others, which suggests that they have high regard for others. Thus, we expected a negative correlation between IS and the Assumed-Competence Scale.

For the third aspect of cognition, cognition about the self in relation to others, we examined the correlation between IS and the Takata Independent/Interdependent Self-Construal Scale. Takata's scale measures independent and interdependent self-construal separately; the former is measured with "individuality" and "dogmatism" subscales, and the latter is measured with "depending on others" and "evaluative apprehension" subscales. People who are high in IS may be inclined to pay attention to evaluations from others; thus, a positive correlation may be found between IS and the evaluative apprehension subscale of the Interdependent Self-Construal Scale. In collectivistic countries such as Japan, concealing one's own attitudes and conforming with others is one way to build good relationships with others and obtain more positive evaluations from them. Conversely, people in collectivistic countries are likely to refrain from clearly stating and affirming their opinions. Such behaviors are more likely to be seen in high-IS people, as they are sensitive to others' estimations of them. Thus, we expected positive correlations between IS and the depending on others subscale of interdependent self-construal, and negative correlations between IS and the two independent self-construal subscales.

\subsection{Hypotheses about PS}

Privileged Self (PS), defined as a tendency to pursue one's own pleasure at the expense of maintaining harmony with others, also produces an effect on interpersonal processes. Although we had no hypothesis relating PS and self-consciousness, we did form hypotheses relating PS to the second and third aspects of cognition investigated. With respect to cognition about others in relation to the self, people with high PS are thought to disregard others, by the following reasoning. When negative evaluations are received from others (e.g., the person makes a mistake at work and receives negative evaluations from colleagues) and this event lowers self-esteem, people may be motivated to restore their self-esteem, and can do so in at least two ways: one is to make an effort (e.g., by working harder) to obtain positive evaluations from others, and the other is to disregard those with negative evaluations of them (e.g., by disregarding colleagues and believing themselves instead). Because the former approach requires effort and is onerous, people high in PS are more likely to take the latter approach; we predicted a positive correlation between PS and the Assumed-Competence Scale.

Regarding cognition about the self in relation to others, we first examined the correlation between PS and the Takata Independent/Interdependent Self-construal Scale. We predicted positive correlations between this scale and PS. Specifically, as stated above, people with high PS are likely to restore self-esteem by 
disregarding others, which predicts a positive correlation between PS and the dogmatism subscale of independent self-construal. People with high PS can also restore self-esteem by concluding that they are so unique that others cannot understand them, which predicts a positive correlation between PS and the individuality subscale of independent self-construal. We predicted a negative correlation between PS and the depending on others subscale of interdependent selfconstrual, because people high in PS pursue their own pleasure at the expense of maintaining harmony with others. No hypothesis about the relationship between PS and the evaluative apprehension subscale of interdependent self-construal was formed.

PS scores may also exhibit a relationship with identity formation. Berzonsky (1989) stressed the problem-solving and decision-making aspects of identity formation, and proposed three identity styles: Information Orientation, Normative Orientation, and Diffuse Orientation. Of the three identity styles, PS may be related to the Diffuse Orientation, because a person with high PS may avoid or procrastinate facing up to negative information about him/herself in order to maintain a high self-evaluation, which is similar to the behavioral characteristics of the Diffuse Orientation style.

\section{Method}

\subsection{Participants and Procedure}

Participants were 439 Japanese undergraduates enrolled in an introductory psychology course (332 male, 104 female, 3 undeclared). Participants completed the questionnaires during a lecture period. We considered that completing all seven questionnaires (131 items) would be undesirable, because completing all items, some of which were similar, would be onerous for the participants, possibly affecting response accuracy, and because the lecture period's duration was insufficient to ensure that all participants would be able to complete all the items in a timely manner. Accordingly, we compiled several different questionnaire batteries and administered them to separate samples. Specifically, 137 (75 male, 62 female) participants completed the Public Self-Consciousness Scale, the SelfPreoccupation Scale, the Takata Independent/Interdependent Self-Construal Scale, and the IPS; 96 (74 male, 19 female, 3 unknown) participants completed the Assumed-Competence Scale, the Identity Style Scale, and the IPS; and 206 participants (183 male, 23 female) participants completed the Interpersonal Sensitivity Measure and the IPS.

\subsection{Measures}

The Interpersonal Sensitivity/Privileged Self Scale (IPS; Muranaka et al., 2017; Yamakawa et al., 2015) was developed to measure the personality features of individuals with MTD, and is assumed to indicate vulnerability factors for MTD. It consists of 25 items divided into two subscales, Interpersonal Sensitivity (IS: 16 items) and Privileged Self (PS: 9 items). Examples of IS items are "I worry that I may be criticized for my words and actions" and "I am able to quickly move on 
even if I'm criticized by those around me" (reverse item). Examples of PS items are "I can't stand people who don't accept my opinion" and "I think my problems are caused by circumstances and people around me." Each item is rated on a 5 -point scale ranging from 1 (very unlike me) to 5 (very like me).

We used the Japanese version (Kuwabara, Sakado, Uehara, Sakado, \& Someya, 1999) of the Interpersonal Sensitivity Measure (IPSM; Boyce \& Parker, 1989). Although this version contains 36 items, we omitted three items that overlapped with the items of IPS, and thus used 33 items. Examples of IPSM items are "I feel insecure when I say goodbye to people" and "I do not like people to really know me." Participants answered each item on a 4-point scale ranging from 1 (very unlike me) to 4 (very like me).

The Public Self-Consciousness Scale (PSC) is a subscale of the Self-Consciousness Scale (Fenigstein et al., 1975). We used the PSC extracted from the Japanese version of the Self-Consciousness Scale (Oshimi, Watanabe, \& Ishikawa, 1985). Examples of PSC items are "Before I leave my house, I check how I look" and "I'm self-conscious about the way I look." The PSC consists of nine items, which are rated from 1 (does not apply to me at all) to 5 (applies to me very well).

The Self-Preoccupation Scale (SPS; Sakamoto, 1998) measures both self-focused attention and how prolonged it is, and consists of 11 items. Its focus is limited to private aspects of the self, such as character, memory, feeling, ability, and the ideal self. Examples of SPS items are "Once I start thinking about myself, I find it difficult to stop" and "I often analyze myself for long periods of time." Each item is rated on 5-point scale from 1 (does not apply to me at all) to 5 (applies to me very well).

The Assumed-Competence Scale, second version (ACS; Hayamizu et al., 2004) consists of 11 items. Each item is a statement that inquires as to the extent to which the participant undervalues others. Examples of the items are "Looking at the way others work, I feel that they are insufficient" and "Looking at the way others work, I feel that they are inefficient." Participants answer using a 5-point scale ranging from 1 (I never think so) to 5 (I often think so).

In the Takata Independent/Interdependent Self-Construal Scale (Takata et al., 1996), the Independent and Interdependent Self-Construal scales consist of 10 items each. The former is composed of "individuality" (4 items) and "dogmatism" (6 items) subscales, and the latter is composed of "depending on others" (6 items) and "evaluative apprehension" (4 items) subscales. Example items are as follows: "I always state my own opinions clearly" (individuality), "It doesn't bother me if my idea or behavior differs from that of others around me" (dogmatism), "How I feel about things depends on who I am with or the situation I am in" (depending on others), and "I am concerned with what others think of me" (depending on others). Participants answer each item on a 7-point scale ranging from 1 (does not apply to me at all) to 7 (applies to me very well).

We used the Japanese version (Niimi, Maeda, \& Kato, 2005) of the Identity Style Inventory (ISI; Berzonsky, 1989), which was developed by translating the 
original version (Berzonsky, 1989) and making to some changes to apply to Japanese undergraduates. This completed version consisted of three subscales (23 items): Informational style (9 items), Normative style (5 items), and Diffuse/ Avoidant style (9 items). An example of a Diffuse/Avoidant style item is "I'm not really thinking about my future now and it's still a long way off." Each item was rated on 5-point scale ranging from 1 (does not apply to me at all) to 5 (applies to me very well).

\subsection{Ethical Considerations}

Ethical approval for the present study was obtained from the university institutional review board. Participants were informed orally as well as on paper that participation in the study was voluntary, that their answers to the questionnaires were anonymous, that they were able to stop responding at any time they wished to, and that participation in the study did not affect their grade. If participants consented to this arrangement, they proceeded to answer the questionnaires. Otherwise, they were able to submit the questionnaires without answering them.

\section{Results}

\subsection{IS Hypothesis Testing (Table 2)}

In examining participants' interpersonal characteristics, we separated these into three aspects of interpersonal cognition. Regarding self-consciousness, we hypothesized that IS would be significantly correlated with scores on the IPSM, PSC, and SPS, which was supported by correlation analyses. That is, we obtained significant correlations of IS with IPSM $(r=.67, p<.001)$, PSC $(r=.60, p$ $<.001)$, and SPS $(r=.57, p<.001)$ after controlling for PS. We also examined cognition about others in relation to the self. We hypothesized that IS would be negatively correlated with ASC scores, which measured the disregarding of others. Correlational analysis showed that PS and ASC were negatively correlated ( $r$ $=-.23, p=.024)$; thus, the hypothesis was supported. In regard to cognition about the self in relation to others, we predicted a positive correlation between IS and two interdependent self-construal subscales; after controlling for PS, the correlations of IS with evaluative apprehension and depending on others were $r$ $=.81(p<.001)$ and $r=.37(p<.001)$ respectively. We also predicted that a negative correlation would be observed between IS and two independent self-construal subscales; after controlling for PS, the correlations of IS with individuality and dogmatism were $r=-.55, p<.001$ and $r=-.51, p<.001$, respectively. Thus, all hypotheses relating to IS were supported.

\subsection{PS Hypothesis Testing (Table 2)}

Of the three aspects of interpersonal cognition investigated, we examined the second and third in relation to PS. The hypothesis for cognition about others in relation to the self was that PS would be positively correlated with ACS scores, which was supported: the correlation between PS and ACS was $r=.58, p<.001$, 
Table 2. Number of data points, alpha coefficients, means, and $S D$ s for each scale, and partial correlations with IS and PS.

\begin{tabular}{|c|c|c|c|c|c|c|c|c|}
\hline & \multirow{3}{*}{$N$} & \multirow{3}{*}{ a } & \multirow{3}{*}{$M$} & \multirow{3}{*}{$S D$} & \multicolumn{4}{|c|}{ Partial correlations with } \\
\hline & & & & & \multicolumn{2}{|c|}{ IS } & \multicolumn{2}{|c|}{ PS } \\
\hline & & & & & $r$ & $p$ & $r$ & $p$ \\
\hline \multicolumn{9}{|l|}{ Self-consciousness } \\
\hline $\begin{array}{c}\text { Interpersonal Sensitivity Measure } \\
\text { (IPSM) }\end{array}$ & 206 & .88 & 81.18 & 13.14 & .67 & $<.001$ & -.06 & .415 \\
\hline $\begin{array}{l}\text { Public Self-Consciousness Scale } \\
\text { (PSC) }\end{array}$ & 138 & .80 & 33.84 & 5.78 & .60 & $<.001$ & .05 & .562 \\
\hline Self-Preoccupation Scale (SPS) & 138 & .88 & 35.11 & 8.71 & .57 & $<.001$ & .26 & .002 \\
\hline \multicolumn{9}{|l|}{ Others in relation to self } \\
\hline $\begin{array}{c}\text { Assumed-Competence Scale, 2nd } \\
\text { ver. (ASC) }\end{array}$ & 96 & .84 & 30.01 & 7.49 & -.23 & .024 & .58 & $<.001$ \\
\hline \multicolumn{9}{|l|}{ Self in relation to others } \\
\hline \multicolumn{9}{|l|}{$\begin{array}{l}\text { Interdependent Self-Construal } \\
\text { Scale }\end{array}$} \\
\hline Depending on others & 138 & .61 & 31.38 & 4.38 & .37 & $<.001$ & -.08 & .339 \\
\hline Evaluative apprehension & 138 & .81 & 20.32 & 4.70 & .81 & $<.001$ & .09 & .318 \\
\hline \multicolumn{9}{|l|}{ Independent Self-Construal Scale } \\
\hline Individuality & 138 & .66 & 16.35 & 3.99 & -.55 & $<.001$ & .13 & .122 \\
\hline Dogmatism & 138 & .71 & 24.41 & 5.46 & -.51 & $<.001$ & .23 & .007 \\
\hline \multicolumn{9}{|l|}{ The Identity Style Inventory (ISI) } \\
\hline Informational Style & 96 & .70 & 33.07 & 4.73 & -.11 & .291 & -.07 & .513 \\
\hline Normative Style & 96 & .35 & 14.98 & 2.66 & -.15 & .155 & .17 & .101 \\
\hline Diffuse/Avoidant Style & 96 & .76 & 22.60 & 5.39 & .12 & .240 & .22 & .029 \\
\hline
\end{tabular}

Mean, $S D$, and alpha coefficients of the scales are presented in the table. Because the two subscales of the IPS (that is, IS and PS) were significantly correlated with each other in each sample $(r=.23-.46)$, we calculated partial correlations between each of these subscales and the other scales administered by controlling for the other IPS subscale.

after controlling for IS. In regard to cognition about the self in relation to others, we hypothesized positive correlations between PS and two independent selfconstrual subscales. Although the predicted correlation with the individuality subscale was not significant $(r=.13, p=.122)$, the correlation with dogmatism was significant $(r=.23, p=.007)$ after controlling for IS. We also predicted a positive correlation between PS and the Diffuse/Avoidant orientation of the ISI, which was supported $(r=.22, p=.029)$ after controlling for IS.

\section{Discussion}

The present study aimed to clarify the interpersonal characteristics of those who score highly on the IPS. Considering three aspects of the interpersonal process, we examined the correlations between the IPS and various scales. Generally speaking, our hypotheses were supported.

\subsection{IS Findings}

Regarding self-consciousness, we hypothesized positive correlations of IS with 
scores on the IPSM, PSC, and SPS, and obtained results that supported these hypotheses. Because the correlations were rather strong $(r=.57-.67)$, we can conclude that persons who are high in IS are concerned with the public self, and engage in prolonged self-focused attention. Similarly, as to cognition about others in relation to the self and the self in relation to others, our hypotheses were also supported. That is, IS was negatively correlated with scores on the ACS and two subscales of independent self-construal, and was positively correlated with two subscales of interdependent self-construal. It is noteworthy that the size of the correlation (after controlling for PS) between IS and dogmatism was almost equal to that of the correlation between IS and individualism $(r=-.55$ and $r=$ -.51 , respectively).

Although interpersonal sensitivity is thought to have a relationship with both MTD and TTD, these characteristics may also be linked to psychological features of anxiety. For example, anxiety is positively correlated with self-focused attention (Mor \& Winquist, 2002, for a review) and the ACS (Suzuki \& Hayamizu, 2015), and is also negatively correlated with independent self-construal (e.g., Moscovitch, Hofmann, \& Litz, 2005; Takata, 1999). Thus, further studies are needed to clarify the relationships among interpersonal sensitivity, anxiety, TTD, and MTD.

\subsection{PS Findings}

With regard to the prediction for cognition about others in relation to the self, we predicted a positive correlation between PS and ASC, and obtained results that supported this hypothesis. People with high PS may disregard others, intentionally or unintentionally, in order to restore their damaged self-evaluation. In connection with cognition about the self in relation to others, we predicted positive correlations between PS and two subscales of the independent self-construal scale, and a negative correlation between PS and the depending on others subscale of the interdependent self-construal scale. A significant correlation was found only between PS and the dogmatism subscale of independent self-construal. We also predicted a positive correlation of PS with scores for the Diffuse/ Avoidant style of ISI, and obtained results supporting this hypothesis.

These results may be interpreted as follows. When people receive negative evaluations from others, and recognize a gap between this and their own positive evaluation of themselves, one response is to believe themselves and assert their own belief. If others are persuaded and accept their view, their evaluations by others are restored. However, as the negative correlation between PS and individuality shows, people with high PS are unlikely to engage in such a strategy. Rather, the positive correlations of PS with dogmatism as well as ACS may suggest that people with high PS disregard others' views and regard themselves as right in a self-satisfied manner. As discussed above, this evidence is corroborated by the positive correlation between PS and the Diffuse/Avoidant identity style. As people with high PS avoid or procrastinate facing negative information about themselves, their self-esteem becomes vulnerable; people who are high in PS do 
not have confidence in themselves. These interpersonal behaviors are characteristic of people with MTD, and not of those with TTD. Thus, in contrast to IS, which may be related both to MTD and to TTD, PS may relate uniquely to MTD.

\subsection{Limitations}

The present study has several limitations. First, this study used a Japanese sample. As cultural background may influence the onset of MTD, replication in other countries is necessary. Second, strong correlations of IS with scores on the IPSM, PSC, and SPS suggest some overlap between IS and other scales. Research discriminating between IS and traits measured by other scales is needed. Third, since the sample consisted of college students not diagnosed with depression, we do not know whether similar results would be obtained in clinical samples. Despite these limitations, our hypotheses about IS and PS were almost completely supported, and the validity of the IPS was demonstrated.

\subsection{Conclusion}

This study has demonstrated several characteristics of people with high IS and PS, which are personality traits thought to interact with interpersonal stressors to engender MTD. The characteristics of people with high IS can be summarized as follows: 1) they are inclined to be concerned with how they are seen by others, 2) they tend to take notice of others, and 3) they have less sense of independent self, but more sense of interdependent self. On the other hand, the characteristics of people with high PS can be summarized as follows: 1) they have a disposition to disregard others, 2) they are somewhat dogmatic, and 3) they tend to have a Diffuse/Avoidant identity style. A challenge for future research will be to demonstrate causal relationships between these personality traits (i.e., IS and PS), interpersonal stressors, and depression using a longitudinal design.

\section{Funding}

This research was supported by the Japan Society for the Promotion of Science, Grants-in-Aid for Scientific Research Grant Number 25380854.

\section{Conflict of Interest}

The authors declare that there is no conflict of interest.

\section{References}

Abramson, L. Y., Alloy, L. B., \& Metalsky, G. I. (1990). Hopelessness Depression: An Empirical Search for a Theory-Based Subtype. In R. E. Ingram (Ed.), Contemporary Psychological Approaches to Depression (pp. 37-58). New York: Plenum Press. https://doi.org/10.1007/978-1-4613-0649-8_4

American Psychiatric Association. (2013). Diagnostic and Statistical Manual of Mental Disorders (5th ed.). Washington DC: Author. https://doi.org/10.1176/appi.books.9780890425596

Berzonsky, M. D. (1989). Identity Style: Conceptualization and Measurement. Journal of 
Adolescent Research, 4, 268-282. https://doi.org/10.1177/0743555488943002

Boyce, P., \& Parker, G. (1989). Development of a Scale to Measure Interpersonal Sensitivity. Australian and New Zealand Journal of Psychiatry, 23, 341-351.

Fenigstein, A., Scheier, M. F., \& Buss, A. H. (1975). Public and Private Self-Consciousness: Assessment and Theory. Journal of Consulting and Clinical Psychology, 43, 522527. https://doi.org/10.1037/h0076760

Hayamizu, T., Kino, K., Takagi, K., \& Tan, E. H. (2004). Assumed-Competence Based on Undervaluing Others as a Determinant of Emotions: Focusing on Anger and Sadness. Asia Pacific Education Review, 5, 127-135. https://doi.org/10.1007/BF03024950

Ingram, R. E. (1990). Self-Focused Attention in Clinical Disorders: Review and a Conceptual Model. Psychological Bulletin, 107, 156-176.

https://doi.org/10.1037/0033-2909.107.2.156

Kato, T. A., Hashimoto, R., Hayakawa, K., Kubo, T., Watabe, M., Teo, A. R., \& Kanba, S. (2016). Multidimensional Anatomy of "Modern Type Depression" in Japan: A Proposal for a Different Diagnostic Approach to Depression beyond the DSM-5. Psychiatry and Clinical Neurosciences, 70, 7-23. https://doi.org/10.1111/pcn.12360

Kato, T. A., Shinfuku, N., Fujisawa, D., Tateno, M., Ishida, T., Akiyama, T.,\& Kanba, S. (2011). Introducing the Concept of Modern Depression in Japan: An International Case Vignette Survey. Journal of Affective Disorders, 135, 66-76. https://doi.org/10.1016/j.jad.2011.06.030

Kuwabara, H., Sakado, K., Uehara, T., Sakado, M., \& Someya, T. (1999). The Japanese Version of the Interpersonal Sensitivity Measure: Its Reliability and Validity. Archives of Psychiatric Diagnostics and Clinical Evaluation, 10, 333-341. (In Japanese)

Mor, N., \& Winquist, J. (2002). Self-Focused Attention and Negative Affect: A MetaAnalysis. Psychological Bulletin, 128, 638-662. https://doi.org/10.1037/0033-2909.128.4.638

Mori, K. (2012a). Is “Modern-Type Depression” Illness or Skipping Out? Shukan-Bunshun, 54, 41-45. (In Japanese)

Mori, K. (2012b). Authorities Warn: "Modern-Type Depression Is Not Depression!" Shukan-Bunshun, 54, 48-51. (In Japanese)

Moscovitch, D. A., Hofmann, S. G., \& Litz, B. T. (2005). The Impact of Self-Construals on Social Anxiety: A Gender-Specific Interaction. Personality and Individual Differences, $38,659-672$.

Muranaka, M., Yamakawa, I., \& Sakamoto, S. (2015). How Do Clinicians Define "Modern Type Depression"? Extraction from Books and the Survey to Clinicians. Psychological Research, Nihon University, 36, 44-51. (In Japanese)

Muranaka, M., Yamakawa, I., \& Sakamoto, S. (2017). Development of the Interpersonal Sensitivity/Privileged Self Scale: The Measurement of a Psychological Characteristic Related to "Modern-Type Depression". Japanese Journal of Psychology, 87, 622-632. (In Japanese)

Niimi, N., Maeda, K., \& Kato, Y. (2005). A Study Confirming the Validity of the Japanese Version of the Identity Style Inventory. Bulletin of the Graduate School of Education, Hiroshima University, Part 3, 54, 275-280. (In Japanese)

Oshimi, T., Watanabe, N., \& Ishikawa, N. (1985). An Examination of the Self-Consciousness Scale. Annual Report of the Department of Psychology, Rikkyo University, 28, 1-15. (In Japanese)

Sakamoto, S. (1998). The Preoccupation Scale: Its Development and Relationship with Depression Scales. Journal of Clinical Psychology, 54, 645-654.

https://doi.org/10.1002/(SICI)1097-4679(199808)54:5<645::AID-JCLP10>3.0.CO;2-D 
Sakamoto, S., Muranaka, M., \& Yamakawa, I. (2014). "Self” in the Interface between Social Psychology and Clinical Psychology: Through Discussion of Modern Type Depression. Japanese Psychological Bulletin, 57, 405-429. (In Japanese)

Sakamoto, S., Yamakawa, I., \& Muranaka, M. (2016). A Comparison of Perceptions of "Modern-Type" and Melancholic Depression in Japan. International Journal of Social Psychiatry, 62, 627-634. https://doi.org/10.1177/0020764016665410

Suzuki, Y., \& Hayamizu, T. (2015). Assumed Competence as Defense Mechanism: Its Relation to Mental Health. Japanese Journal of Research on Emotions, 23, 23-31. (In Japanese) https://doi.org/10.4092/jsre.23.23

Takata, T. (1999). Developmental Process of Independent and Interdependent Self-Construal in Japanese Culture: Cross-Cultural and Cross-Sectional Analyses. Japanese Journal of Educational Psychology, 47, 480-489. (In Japanese)

https://doi.org/10.5926/jjep1953.47.4_480

Takata, T., Omoto, M., \& Seike, M. (1996). Construction of a Revised Scale for Independent and Interdependent Construal of Self. Memoirs of the Nara University, 24, $157-$ 173. (In Japanese)

Tarumi, S. (2005). The "New" Variant of Depression: The Dysthymic Type. Japanese Journal of Clinical Psychiatry, 34, 687-694. (In Japanese)

Tarumi, S., \& Kanba, S. (2005). The Dysthymic Type of Depression: An Essay on Socio-Cultural Aspects of Depression. Japanese Bulletin of Social Psychiatry, 13, 129-136. (In Japanese)

Yamakawa, I., Muranaka, M., \& Sakamoto, S. (2015). Validity and Reliability of the Interpersonal Sensitivity/Privileged Self Scale: Solving a New Type of Depression. Psychology, 6, 1013-1021. https://doi.org/10.4236/psych.2015.68098

\section{Submit or recommend next manuscript to SCIRP and we will provide best service for you:}

Accepting pre-submission inquiries through Email, Facebook, LinkedIn, Twitter, etc. A wide selection of journals (inclusive of 9 subjects, more than 200 journals)

Providing 24-hour high-quality service

User-friendly online submission system

Fair and swift peer-review system

Efficient typesetting and proofreading procedure

Display of the result of downloads and visits, as well as the number of cited articles

Maximum dissemination of your research work

Submit your manuscript at: http://papersubmission.scirp.org/

Or contact psych@scirp.org 